\title{
A Case of Acquired von Willebrand Disease Secondary to Myeloproliferative Neoplasm
}

\author{
Sreethish Sasi ${ }^{a} \quad$ Mohamed A. Yassin ${ }^{b} \quad$ Afraa M. Fadul ${ }^{b}$ \\ aDepartment of Internal Medicine, Hamad General Hospital, Hamad Medical Corporation, \\ Doha, Qatar; ${ }^{b}$ Department of Hematology, National Center for Cancer Care and Research, \\ Hamad Medical Corporation, Doha, Qatar
}

\section{Keywords}

Acquired von Willebrand disease $\cdot$ Myeloproliferative neoplasms · Essential

thrombocythemia · Pegylated interferon alfa2a

\begin{abstract}
Acquired von Willebrand Disease (AVWD) is a rare disorder in which qualitative or quantitative defects in von Willebrand factor (VWF) occur secondary to other conditions. AVWD occurs in patients with myeloproliferative disorders due to formation of autoantibodies against VWF and development of excessive shear stress causing disruption of VWF multimers. AVWD is different from congenital VWD in its acute onset and absence of family history. We report a 42-year-old gentleman with essential thrombocythemia, who was on cytoreductive therapy with hydroxyurea, and presented with an acute history of gum bleeding with hemoptysis, without any antecedent trauma or infections. His platelet count was very high, and prothrombin time and activated partial thromboplastin time were prolonged. The VWF ristocetin cofactor assay (VWF: RCo) was low, but VWF antigen level (VWF: Ag) was normal. Their ratio (VWF: RCo/VWF: Ag) was much lower than the acceptable lower limit. Treatment in AVWD is focused on addressing the underlying disorder. Early recognition of AVWD and its primary cause is mandatory in providing adequate therapy and achieving a cure.

\section{Introduction}

Von Willebrand factor (VWF) is an abundant protein with numerous monomers. It is produced by endothelial cells, subendothelial connective tissue, and megakaryocytes. VWF that is attached to the subendothelial connective tissue has protein monomers responsible 
for adhesion and aggregation of platelets. Circulating VWF has protein monomers that bind factor VIII. A metalloproteinase enzyme, ADAMSTS13, cleaves and regulates the size of VWF. Most cases of von Willebrand disease (VWD) are inherited and may be due to qualitative (type 2) or quantitative (type 1 or type 3) abnormalities in VWF. Hereditary VWD is the most common congenital bleeding disorder. Acquired von Willebrand disease (AVWD) is scarce and occurs later in life, associated with other diseases and without a family history of bleeding. Clinical presentation of both acquired and hereditary VWD is similar, which is usually mild to moderate bleeding from mucocutaneous surfaces. Unlike hereditary, the diagnosis of AVWD is very complex and underestimated.

\section{Case Report/Case Presentation}

A 42-year-old gentleman approached the emergency department with complaints of bleeding from his gums for 5 days and coughing of blood for a day. He coughed up a spoonfull size of frank blood three times. He denied any preceding fever or symptoms of upper respiratory tract infection. He did not have any recent productive cough or shortness of breath. He had normal bowel and bladder habits. There was no history of red urine or dark stool. He did not notice any joint swellings or skin rash. He did not complain of any bruises and did not remember any recent trauma. He denied any unintentional weight loss in the recent past. He had an episode of bleeding from gums 2 years back, for which he did not seek any medical help as it self-resolved in a couple of days.

His past history was significant for an episode of abdominal distention 20 years back in Pakistan. He was found to have splenomegaly and underwent splenectomy at a local medical facility. However, the etiology of splenomegaly was undetermined, and he had no medical records available. He was also found to have thrombocytosis at that point and was started on hydroxyurea, which he continued for several years until stopping it a year back, without medical advice. He had bilateral pulmonary embolism 7 years ago and was started on rivaroxaban since then. He did not report any abnormal bleeding manifestations in the last 7 years, except for the gum bleeding 2 years back, and did not have any regular follow-ups. Family history was negative for easy bruising, bleeding, or clotting disorders. He was a smoker with 20 pack-years of smoking history.

The physical examination was unremarkable. There were no bruises or bleeding in any extremities. The chest and abdomen were grossly normal. Lab tests at the time of presentation showed leukocytosis, erythrocytosis, and marked thrombocytosis. Manual platelet count was 2,300,000. Hemoglobin level and hematocrit were normal. The differential count showed a uniform increase in all components (Table 1). Peripheral smear showed hypochromic microcytic red cells with relative erythrocytosis, reticulocytosis, and features of hyposplenism. There was marked thrombocytosis and presence of giant forms. Reticulocyte count was 3.8\%. Hemoglobin electrophoresis showed a high hemoglobin A2 with the low red cell indices consistent with beta-thalassemia trait. Kidney and liver functions were normal, but the potassium level was 6. Lactate dehydrogenase (530) was high and haptoglobin was normal. Coagulation panel showed a prolonged prothrombin time-international normalized ratio $(13.8,1.3)$ and activated partial thromboplastin time (40.7). Factor VIII level was normal. The von Willebrand panel showed that his VWF ristocetin cofactor assay (VWF: RCo) was low, but VWF antigen level (VWF: Ag) was normal. Their ratio (VWF: RCo/VWF: Ag) was much lower than the acceptable lower limit (Table 2). All infection and autoimmune workups were negative. Light-cycler analysis of genomic DNA from blood was positive for the JAK2V617F, consistent with a diagnosis of myeloproliferative neoplasm (MPN). However, fragment analysis of DNA from blood did not show any mutation within exon 9 of the CALR gene. There 
Table 1. Complete and differential cell counts on admission

Sasi et al.: Acquired von Willebrand Disease

\begin{tabular}{lrc}
\hline Detail & Value & Normal range \\
\hline $\mathrm{WBC}, \times 10^{3} / \mu \mathrm{L}$ & 18.9 & $4.0-10.0$ \\
$\mathrm{RBC}, \times 10^{6} / \mu \mathrm{L}$ & 6.3 & $4.5-5.5$ \\
$\mathrm{Hgb}, \mathrm{g} / \mathrm{dL}$ & 13.9 & $13.0-17.0$ \\
$\mathrm{HCT}, \%$ & 44.7 & $40.0-50.0$ \\
$\mathrm{MCV}, \mathrm{fL}$ & 71.1 & $83.0-101.0$ \\
$\mathrm{MCH}, \mathrm{pg}$ & 22.1 & $27.0-32.0$ \\
$\mathrm{MCHC}, \mathrm{g} / \mathrm{dL}$ & 31.1 & $31.5-34.5$ \\
$\mathrm{RDW}-\mathrm{CV}, \%$ & 19.7 & $11.6-14.5$ \\
Absolute neutrophil count, $\times 10^{3} / \mu \mathrm{L}$ & 11.6 & $2.0-7.0$ \\
Lymphocytes, $\times 10^{3} / \mu \mathrm{L}$ & 4.1 & $1.0-3.0$ \\
Monocytes, $\times 10^{3} / \mu \mathrm{L}$ & 1.6 & $0.2-1.0$ \\
Eosinophils, $\times 10^{3} / \mu \mathrm{L}$ & 1.2 & $0.0-0.5$ \\
Basophils, $\times 10^{3} / \mu \mathrm{L}$ & 0.33 & $0.02-0.10$ \\
Platelets, $\times 10^{3} / \mu \mathrm{L}$ & 2,159 & $150-400$ \\
\hline
\end{tabular}

Table 2. Von Willebrand panel (patient blood group: AB positive)

\begin{tabular}{lcl}
\hline Detail & Value & Normal range \\
\hline Factor VIII levels (FVIII:C) & $114.6 \%$ & $70.0-150.0 \%$ \\
VWF antigen level (VWF: Ag) & $102.7 \%$ & $65.5-187.5 \%$ \\
VWF ristocetin cofactor assay (VWF: RCo) & $25.7 \%$ & $63.3-199.7 \%$ \\
VWF: RCo/VWF: Ag & 0.25 & $>0.7$ \\
\hline
\end{tabular}

was no BCR-ABL1 gene fusion shown by single-step RT-PCR. Bone marrow was hypercellular showing trilineage hematopoiesis with panmyelosis. Megakaryocytes showed pleomorphism and there were mildly increased reticulin fibers (MF 1). Peripheral blood and bone marrow findings were also consistent with MPN.

\section{Discussion/Conclusion}

MPNs are a group of disorders due to stem-cell hyperplasia characterized by an increased peripheral blood cell count, overactive bone marrow, and proliferation of mature hematopoietic cells [1]. Chronic myeloid leukemia, essential thrombocythemia (ET), polycythemia vera, and myelofibrosis are designated as MPNs, with the last three not showing BCR-ABL1 gene fusion (Philadelphia chromosome). Patients with MPNs are faced with a high diseaserelated symptom burden, and quality of life decrements, despite being on treatment [2]. In Qatar, familial cases of MPNs are more frequently seen than mentioned in the literature. Al-Dewik et al. in 2019, described the complexity of the genotype of patients with MPNs in Qatar using clinical exome sequencing [3]. ET is a chronic myeloproliferative disorder due to sustained proliferation of megakaryocytes. ET is documented in twenty-five families from five major tribes in Qatar. Twenty of them were having JAK2V617F positivity in three consecutive generations while four others had familial ET in three generations but both JAK2V617F and MPL were negative [4]. Patients with low-risk ET are managed with low-dose of acetylsalicylic acid, while those with high-risk disease need cytoreductive treatment. Hydroxyurea is the first choice and anagrelide is the alternative in those with resistance or intolerance. Another option is interferon alfa2a (pegasis), which can induce cytogenetic remissions or reversion from monoclonal to polyclonal patterns of hematopoiesis. $135 \mu$ g pegasis once 
monthly is as effective as once-weekly dose with reduced toxicity [5]. Most cases of AVWD are seen in patients with lymphoproliferative disorders (30-48\%), myeloproliferative disorders (15-18\%), cardiovascular disorders (12-21\%), neoplasia (5-6\%), and immune deficiencies (2-6\%) [6]. The major pathophysiological mechanism is the development of IgG autoantibodies against VWF. AVWF is more common in ET than in polycythemia vera or myelofibrosis, as the increased number of platelets in blood are subject to greater shear stress while they pass through the capillaries, stimulating the adsorption of VWF multimers onto the platelet membranes resulting in their degradation and subsequent removal from circulation [7]. Diagnosis for VWD is made by laboratory testing of the quantity of VWF antigen that is present in plasma (VWF: Ag) and the efficacy of this plasma VWF in its ability to bind platelets in the presence of the antibiotic ristocetin (VWF: RCo). A combination of these tests plus the measurement of coagulation factor VIII (FVIII:C), allows for the classification of patients into the classic groupings of VWD type 1 or type 2. VWD type 1 commonly results in a concomitant depression in both VWF: RCo and VWF: Ag and their ratio tends to remain around 1. Conversely, in VWD type 2, where the function of VWF is decreased to a greater extent than the amount of protein, the VWF: RCo decrease is disproportionate to the VWF: Ag level. Thus, a ratio of less than 0.6 is often indicative of VWD type 2. Unlike congenital VWD, the onset of AVWD is recent or short-term and there is no evident family history of bleeding $[8,9]$. Treatment in AVWD is aimed at controlling acute bleeds, preventing highrisk bleeds and obtaining long-term remission. Most strategies are focused on addressing the underlying disorder. In ET, it includes cytoreductive therapy, chemotherapy, or stem cell transplantation in case of progression. General approaches to control bleeding in AVWD patients are administering desmopressin in doses of $0.3 \mu \mathrm{g} / \mathrm{kg}$ over $30 \mathrm{~min}$ once or twice daily, VWF-containing concentrates at 30-100 VWF: RCo units/kg, recombinant factor VIIA at a dose of $90 \mu \mathrm{g} / \mathrm{kg}$, antifibrinolytic drugs, intravenous immunoglobulin at $1 \mathrm{~g} / \mathrm{kg} /$ day for 2 days, and plasmapheresis [10]. VWS is a complex multicausal disorder. Early recognition of acquired VWS and its primary cause is mandatory in providing adequate therapy and achieving a cure.

\section{Acknowledgment}

The authors would like to acknowledge Internal Medicine Residency Program for scientific support.

\section{Statement of Ethics}

The case was approved by Hamad Medical Corporation Medical Research Center. Written informed consent was given by the patient to publish his case information and details.

\section{Conflict of Interest Statement}

The authors have no conflicts of interest to declare.

\section{Funding Sources}

The publication of this article was funded by the Qatar National library. 
Sasi et al.: Acquired von Willebrand Disease

\section{Author Contributions}

Sreethish Sasi: manuscript writing. He will act as a study guarantor. Mohamed A. Yassin: concept, manuscript review, and manuscript editing. Afraa M. Fadul: clinical care and patient management.

\section{References}

1 Tefferi A, Vardiman JW. Classification and diagnosis of myeloproliferative neoplasms: The 2008 World Health Organization criteria and point-of-care diagnostic algorithms. Leukemia. 2008 Jan;22(1):14-22.

2 Yassin M, Taher A, Mathews V, Hou H-A, Shamsi T, Tuglular T, et al. Myeloproliferative neoplasms in Asia, including Middle East, Turkey, and Algeria: epidemiological indices and treatment practice patterns from the multinational, multicenter, observational MERGE registry. Cancer Medicine. 30 April 2020;4(3004):1-15. 10.1002/cam4.3004 . https://onlinelibrary.wiley.com/doi/pdf/10.1002/cam4.3004. 32351024.

3 Al-Dewik N, Ben-Omran T, Zayed H, Trujillano D, Kishore S, Rolfs A, et al. Clinical Exome Sequencing unravels new disease-causing mutations in the myeloproliferative neoplasms: a pilot study in patients from the state of Qatar. Gene. 2019 Mar 20;689:34-42.

4 Yassin MA, Al-Dewik NI, ElAyoubi H, Cassinat B. Familial essential thrombocythemia among Qatari tribes. Blood. 2013 Nov 15;122(21):5244.

5 Yassin MA, Al-Dewik NI, ElAyoubi H, Cassinat B. Efficacy and safety of pegelated interferon alpha2a once monthly compared to once weekly dose in patients with essential thrombocythemia. Blood. 2013 Nov 15; 122(21):4054.

6 Claus P-E, Van Haute I, Verhoye E, Deeren D, Moreau E. Diagnostic challenges in acquired von Willebrand disease: a complex case of prostate carcinoma. J Hematol. 2016 Oct 12;5(3):110-2.

7 Budde U, Scharf RE, Franke P, Hartmann-Budde K, Dent J, Ruggeri ZM. Elevated platelet count as a cause of abnormal von Willebrand factor multimer distribution in plasma. Blood. 1993 Sep 15;82(6):1749-57.

8 Ng C, Motto DG, Di Paola J. Diagnostic approach to von Willebrand disease. Blood. 2015 Mar 26;125(13):202937.

9 Franchini M, Lippi G, Favaloro EJ. Advances in hematology. Etiology and diagnosis of acquired von Willebrand syndrome. Clin Adv Hematol Oncol. 2010;8(1):20-4.

10 Tiede A, Rand JH, Budde U, Ganser A, Federici AB. How I treat the acquired von Willebrand syndrome. Blood. 2011 Jun 23;117(25):6777-85. 